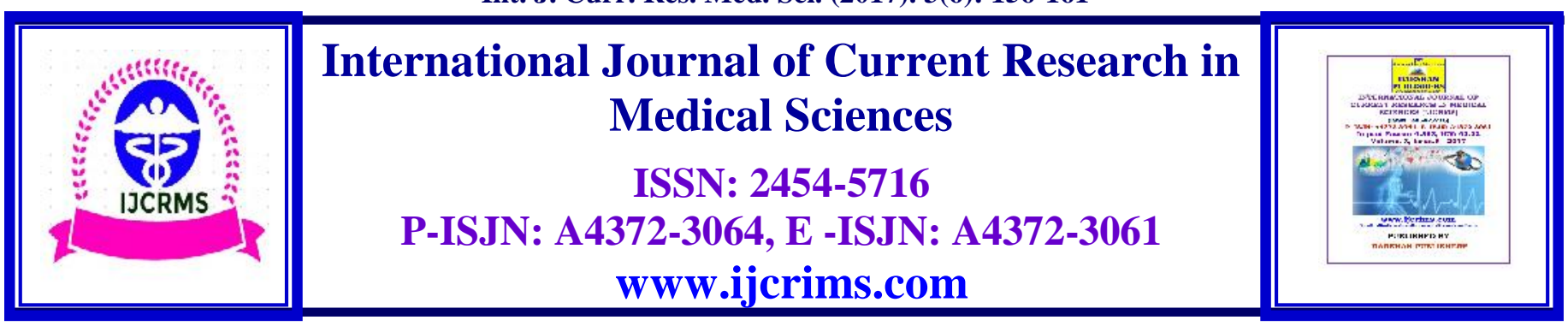

\title{
PPIUCD- Expanding Horizons in Contraception in Indian Scenario
}

\author{
* Preetkanwal Sibia, **Parneet Kaur, ***Surbhi Saini, ****Anju \\ *Associate Professor, **Professor, ***Junior Resident,****Assistant Professor, Dept. of Obstetrics \& \\ Gynaecology, Govt. Medical College, Patiala, Punjab, India, 147001 \\ Corresponding Author: Dr. Preetkanwal Sibia, Associate Professor, Dept. of Obstetrics \& Gynaecology, \\ Govt. Medical College, Patiala, 147001, India \\ E-mail:drsibial@yahoo.com
}

\begin{abstract}
Interest in Postpartum Intrauterine Contraceptive Device (PPIUCD) has increased over the recent time. It has been recognized as a promising tool in answering the unmet need for contraception. In this five year study we observed $10.6 \%$ insertions out of more than 16000 deliveries, with increasing insertions over the years. Time of counseling for the acceptors was early labor (93.04\%), antenatal period $(4.75 \%)$ and post-partum period $(2.20 \%)$. Technique of insertions was PPIUCD forceps (73.91\%), Manual (16.64\%) and Sponge-holding forceps (9.45\%). Timing of insertions was intra-cesarean (50.03\%), post-placental (47.30\%) and immediate (2.67\%). Follow up was available in $59.19 \%$ cases, via clinic visits (53.08\%) and telephonic calls (46.91\%).Expulsion rates varied from 2.66 to $6.85 \%$. Removal rate varied from 8.90 to $35.00 \%$.
\end{abstract}

Keywords: Contraception, Counseling, Family planning, Intrauterine device, Postpartum, Pregnancy, Sterilization

\section{Introduction}

India contributes about $20 \%$ of births worldwide. Approximately $61 \%$ ofthese occur at intervals shorter than recommended birth to birth interval of approximately 36 months.Intrauterine contraception is the most cost-effective method of contraception today. Many women also find the Intrauterine Contraceptive Devices (IUCD) to be very convenient; because it requires little attention once it is inserted.[1]Provision of IUCD in the immediate postpartum period (PP) offers an effective and safe method for spacing and limiting births.
A good counseling cannot be overlooked in this regard. Many of these women welcome the opportunity to delay their next pregnancy when are counseled well. Opportunity for a success is excellent, because delivery provides a convenient opportunity for the woman to receive IUCD services.This is particularly important for women who have limited access to medical care. A new mother is likely to be motivated to consider longacting methods.[1,2] 
IUCD can be inserted safely at any time during the first $48 \mathrm{~h}$ after delivery, can also be inserted after 6 weeks postpartum (Extended PP) and after an abortion (Post-abortal).

Despite the many advantages of the IUCD as a method of family planning, it generally suffers from unpopularity in India.The age old myths are the biggest hindrance in choosing this as a contraceptive method.

Resurgence in interest in Postpartum Intrauterine Contraceptive Device (PPIUCD) increased in the recent time as increasing numbers of women in India are having their babies born in hospitals after introduction of Janani Suraksha Yojana (JSY) (Mother Security Scheme) and Janani Shishu Suraksha Karyakram (JSSK) (Mother Child Security Program). It allows opportunity for the state to provide PPIUD in a big way whereimmediate postpartum insertion is convenient for the acceptor and provider both. New advances and understanding aboutPPIUCD have proved it to be safe andeffective. IUCD as spacing and long- term reversible method is getting popularized as an alternative to sterilization among couples in recent time.[3]

In India, the 2005-2006 National Family Health Survey (NFHS) reported that $61 \%$ of births were spaced less than three years[4] and that $22 \%$ of married women had an unmet need for family planning. A subsequent stratified analysis suggested that $65 \%$ of women in the first year postpartum had an unmet need for family planning.[5] IUCDs are used by only two percent of current users of contraception in India.[4] Recognizing the potential impact of improved family planning programming on maternal and child health, the Government of India has committed to expanding access to family planning as part of achieving Millennium Development Goals 4 and 5, related to reduction of child and maternal mortality. In 2005, the Government of India launched the Janani SukrakshaYojana (JSY), a conditional cash transfer scheme, to encourage the use of facilities for care at birth.[6] Since the inception of JSY, facility-based births in the public sector have increased from 700,000 in 2005 more than 11 million in 2012.[7]
The Ministry of Health and Family Welfare, Govt. of India introduced PPIUCD service in 19 states of India in 2010, in collaboration with Jhpiego, India.[8]

PPIUCD has been recognized as a promising tool in answering the unmet need for contraception in the country by the health authorities and strong steps has been taken to strengthen it.

\section{Materials and Methods}

A 5 year study was conducted in our institution.Women admitted and delivered here were counseled in antenatal period and early labor.PPIUCDwas inserted in accepters who fulfilled the Medical Eligibility Criteria and had no contraindications for PPIUCD. The insertions were done intra-Cesarean, post-placental and in immediate post-partum period. The technique was manual or by using PPIUD insertion forceps or sponge holding forceps. They were followed up in clinic and telephonically for side effects, complications and continuation.

\section{Results and Discussion}

In our study, over the 5 years, the average number of deliveries in a year was 3256 . The total number of PPIUCD insertions increased over the successive years with proper counseling and training among the providing staff. With the commencement of the program in 2011 total insertions were $3.63 \%$ which rose to $14.76 \%$ in the fifth year of study.

Millions of women worldwide would prefer to avoid becoming pregnant either right away or never get pregnant, but are not using any contraception. These women are said to have an "unmet need" for family planning (FP). The concept of unmet need points to the gap between some women's reproductive intentions and their contraceptive behavior. Unmet need can be a powerful concept for FP programs.[9]

The postpartum period provides opportunity to the health care provider for counseling a woman, regarding the available family planning methods, including IUD insertion, to avoid unintended conceptions. It is observed that women who have 
been counseled for postpartum IUCD insertion have 10 times higher chance of using IUCD, than those, where insertion was delayed till complete involution of the uterus.[10]

Among the options available, the multi-year cost of the Copper T380A IUD makes it one of the most cost-effective contraceptive options available. The Copper $\mathrm{T} 380 \mathrm{~A}$ intra-uterine contraceptive device (IUCD) is a highly effective, non-hormonal method that can be safely used by all women regardless of breastfeeding status during this interval. According to the World Health Organization Medical Eligibility Criteria, an IUCD can be inserted in the 48 hours postpartum, referred to here as a postpartum IUCD (PPIUCD), or after four weeks following a birth.[11] A 2010 Cochrane review concluded that PPIUCDs were a safe and effective contraceptive method. The public health benefits from PPIUCDs stemmed from the women's increased accessibility to PPIUCDs following facility births, as PPIUCDs could be offered at health facilities after childbirth. This, in turn, decreased opportunity and other costs incurred by clients who may otherwise have to return to facilities to access contraceptive services.[12]

PPIUCD program was introduced in our institution in August 2011. During the 5 years from the commencement there have been 1725 PPIUCD insertions out of total 16281 deliveries conducted in the institution. There were $10.60 \%$ acceptors among the parturients.

In our study $4.75 \%$ acceptors had received counseling about PPIUCD in their antenatal period. The rest of the $93.04 \%$ acceptors were counseled during early labor. Many studies have shown that when the partner is involved in contraceptive counseling and Decision making, the acceptance and continuation rates were higher. Unfortunately in our setup, women who visit the antenatal clinic are usually not accompanied by their partners, and the care providers do not allow them during the process even if they are present.Thus, couple counseling is lost during this period. Furthermore, during the short postpartum period, which is not appropriate for counseling, to get consent from a partner having no knowledge about PPIUCD is difficult. Therefore, it is most important to include proper counseling of the couple together to choose a contraceptive method which will in turn increase the compliance.

In our study we followed up 59.19\% acceptors. The follow up was done in the clinic and by telephone for those acceptors who did not return to the clinic after 6 weeks of insertion. Among our acceptors, $40.81 \%$ were lost to follow up after 6 months. In a study conducted by Mishra (2014), as many as $59.98 \%$ acceptors were seen in the clinic after 6 weeks and $18.97 \%$ over telephone. They had a loss of $23.05 \%$ acceptors to follow up in their study.[1]Manju et al (2000), found that $21.38 \%$ clients had lost to follow up at 4-6 weeks post-partum and only $11.37 \%$ clients returned at 6 month follow up.[13]

Amongst the followed up acceptors $17 \%$ complained of missing threads, $11 \%$ had pain and $19 \%$ increased vaginal bleeding as their chief complaint. There we no cases reported of infection, perforation or pregnancy with PPIUCD in utero. Mishra (2014) observed 23.5\% acceptors visiting the clinic with complaints of bleeding and $8.69 \%$ with missing strings.[1] Our observations were similar to those found in other studies assessing the efficacy of PPIUCD. Women most commonly reported expected side effects of IUCDs as the reasons for the removal, including bleeding and abdominal pain. These findings suggest that there is room for strengthening PPIUCD counseling services, particularly regarding normal side effects and complications that arise from method use.

Previously, concerns about the PPIUCD focused on high expulsion rates. Studies published in the nineties and early 2000 reported rates of about 913\%.[14-16] However, lower expulsion rates have been reported more recently with improvements in insertion technique.[17,18] In our study, total expulsion rate was $5.12 \%$ and total removal rate was $10.35 \%$ over the five years. $92 \%$ reported satisfaction at the six-week follow-up visit. The rate of expulsion of IUCD was $3.6 \%$ by six weeks of follow-up. 
Int. J. Curr. Res. Med. Sci. (2017). 3(6): 156-161

Table1. Total deliveries and insertions

\begin{tabular}{|c|c|c|c|}
\hline Year & Total deliveries & Total insertions & $\%$ \\
\hline Aug 2011- Jul 2012 & 2479 & 90 & 3.63 \\
\hline Aug 2012- Jul 2013 & 2959 & 256 & 8.65 \\
\hline Aug 2013- Jul 2014 & 3638 & 432 & 11.87 \\
\hline Aug 2014- Jul 2015 & 3905 & 460 & 11.78 \\
\hline Aug 2015- Jul 2016 & 3300 & 487 & 14.76 \\
\hline Total & 16281 & 1725 & 10.60 \\
\hline
\end{tabular}

Table 2. Time of counseling for the acceptors

\begin{tabular}{|c|c|c|c|c|c|c|}
\hline \multirow{2}{*}{ Year } & \multicolumn{2}{|c|}{ Antenatal period } & \multicolumn{2}{c|}{ Early labor } & \multicolumn{2}{c|}{ Post-partum } \\
\cline { 2 - 6 } & $\mathrm{N}$ & $\%$ & $\mathrm{~N}$ & $\%$ & $\mathrm{~N}$ & $\%$ \\
\hline Aug 2011- Jul 2012 & 3 & 3.33 & 84 & 93.33 & 3 & 3.33 \\
\hline Aug 2012- Jul 2013 & 5 & 1.95 & 244 & 95.31 & 7 & 2.73 \\
\hline Aug 2013- Jul 2014 & 7 & 1.62 & 417 & 96.53 & 8 & 1.85 \\
\hline Aug 2014- Jul 2015 & 32 & 6.96 & 418 & 90.87 & 10 & 2.17 \\
\hline Aug 2015- Jul 2016 & 35 & 7.19 & 442 & 90.76 & 10 & 2.05 \\
\hline Total & 82 & 4.75 & 1605 & 93.04 & 38 & 2.20 \\
\hline
\end{tabular}

Table 3.Technique of insertion

\begin{tabular}{|c|c|c|c|c|c|c|}
\hline \multirow{2}{*}{ Year } & \multicolumn{2}{|c|}{ PPIUCD forceps } & \multicolumn{2}{|c|}{ Sponge holding forceps } & \multicolumn{2}{c|}{ Manual } \\
\cline { 2 - 6 } & $\mathrm{N}$ & $\%$ & $\mathrm{~N}$ & $\%$ & $\mathrm{~N}$ & $\%$ \\
\hline Aug 2011- Jul 2012 & 79 & 87.78 & 10 & 11.11 & 1 & 1.11 \\
\hline Aug 2012- Jul 2013 & 227 & 88.67 & 27 & 10.55 & 2 & 0.78 \\
\hline Aug 2013- Jul 2014 & 273 & 63.19 & 24 & 5.56 & 135 & 31.25 \\
\hline Aug 2014- Jul 2015 & 294 & 63.91 & 62 & 13.48 & 104 & 22.61 \\
\hline Aug 2015- Jul 2016 & 402 & 82.55 & 40 & 8.21 & 45 & 9.24 \\
\hline Total & 1275 & 73.91 & 163 & 9.45 & 287 & 16.64 \\
\hline
\end{tabular}

Table 4.Timing of insertion

\begin{tabular}{|c|c|c|c|c|c|c|}
\hline \multirow{2}{*}{ Year } & \multicolumn{2}{|c|}{ Post placental } & \multicolumn{2}{c|}{ Intra-Cesarean } & \multicolumn{2}{c|}{ Immediate } \\
\cline { 2 - 6 } & $\mathrm{N}$ & $\%$ & $\mathrm{~N}$ & $\%$ & $\mathrm{~N}$ & $\%$ \\
\hline Aug 2011- Jul 2012 & 30 & 33.33 & 47 & 52.22 & 13 & 14.44 \\
\hline Aug 2012- Jul 2013 & 94 & 36.72 & 159 & 62.11 & 3 & 1.17 \\
\hline Aug 2013- Jul 2014 & 153 & 35.42 & 269 & 62.27 & 10 & 2.31 \\
\hline Aug 2014- Jul 2015 & 233 & 50.65 & 216 & 46.96 & 11 & 2.39 \\
\hline Aug 2015- Jul 2016 & 306 & 62.83 & 172 & 35.32 & 9 & 1.85 \\
\hline Total & 816 & 47.30 & 863 & 50.03 & 46 & 2.67 \\
\hline
\end{tabular}


Int. J. Curr. Res. Med. Sci. (2017). 3(6): 156-161

Table 5. First clinic follow up visit

\begin{tabular}{|c|c|c|c|c|}
\hline \multirow{2}{*}{ Year } & \multicolumn{2}{|c|}{$<6$ weeks } & \multicolumn{2}{c|}{$>6$ weeks } \\
\cline { 2 - 5 } & Number of acceptors & $\%$ & Number of acceptors & $\%$ \\
\hline Aug 2011- Jul 2012 & 5 & 25.00 & 15 & 75.00 \\
\hline Aug 2012- Jul 2013 & 43 & 69.35 & 19 & 30.65 \\
\hline Aug 2013- Jul 2014 & 38 & 31.40 & 83 & 68.60 \\
\hline Aug 2014- Jul 2015 & 14 & 8.48 & 151 & 91.52 \\
\hline Aug 2015- Jul 2016 & 20 & 11.49 & 154 & 88.51 \\
\hline Total & 120 & 22.14 & 422 & 77.86 \\
\hline
\end{tabular}

Table 6. First cumulative follow up visit(clinic + telephonic)

\begin{tabular}{|c|c|c|c|c|c|}
\hline \multirow{2}{*}{ Year } & Total Insertions & \multicolumn{4}{|c|}{ Follow Up } \\
\cline { 3 - 6 } & & Clinic & Telephonic & $\mathrm{N}$ & $\%$ \\
\hline Aug 2011- Jul 2012 & 90 & 20 & 0 & 20 & 22.22 \\
\hline Aug 2012- Jul 2013 & 256 & 62 & 15 & 177 & 30.08 \\
\hline Aug 2013- Jul 2014 & 432 & 121 & 180 & 301 & 69.68 \\
\hline Aug 2014- Jul 2015 & 460 & 165 & 156 & 321 & 69.78 \\
\hline Aug 2015- Jul 2016 & 487 & 174 & 128 & 302 & 62.01 \\
\hline Total & 1725 & 542 & 479 & 1021 & 59.19 \\
\hline
\end{tabular}

Table 8. Expulsion and removal rate

\begin{tabular}{|c|c|c|}
\hline Year & Expulsion rate(\%) & Removal rate(\%) \\
\hline Aug 2011- Jul 2012 & 5.00 & 35.00 \\
\hline Aug 2012- Jul 2013 & 4.79 & 8.90 \\
\hline Aug 2013- Jul 2014 & 2.66 & 10.30 \\
\hline Aug 2014- Jul 2015 & 6.85 & 8.73 \\
\hline Aug 2015- Jul 2016 & 6.04 & 11.72 \\
\hline
\end{tabular}

\section{Conclusion}

PPIUCD has high retention rate. Government initiative for awareness, training of healthcare providers and cash incentives for acceptor, motivator and provider are promising. PPIUCD has a huge potential and abundant scope in India and if widely used it will have a strong impact on population control and will prevent unplanned pregnancy and its sequel

\section{Source of funding: Nil}

Conflict of interest: None declared

\section{References}

1. Mishra S. Evaluation of Safety, Efficacy, and Expulsion of Post-Placental and Intra-Cesarean Insertion of Intrauterine Contraceptive Devices
(PPIUCD). J Obstet Gynaecol India. 2014;64(5):337-43.

2. Bedi PK, Guliani MS, Bala S. A prospective study to assess the safety and expulsion rate of copper T380A in immediate post-partum period during caesarean section. Int J Reprod Contracept Obstet Gynecol. 2016;5(9):3195-9.

3. Lopez LM, Bernholc A, Hubacher D, Stuart G, Van Vliet HAAM. Immediate postpartum insertion of intrauterine device for contraception. Cochrane Database Syst Rev. 2015 Jun 26;(6):CD003036.

4. International Institute for Population Sciences (IIPS), Macro International. National Family Health Survey (NFHS-3), 2005-06: India [Internet]. Mumbai: IIPS; 2007 [cited 2017 Jun 3] p. 540. Available from: http://rchiips.org/NFHS/nfhs3_national_report. shtml

5. Borda M. Family planning needs during the extended postpartum period in India [Internet]. 
Baltimore, Maryland: Jhpiego, Access to Clinical and Community Maternal, Neonatal and Women's Health Services (ACCESS), Family Planning Initiative [ACCESS-FP]; 2009 [cited 2017 Jun 3] p. 4. Report No.: USAID Associate Cooperative Agreement No. GPO-A-00-05-00025-00. Available from: http://www.popline.org/node/210717

6. Lim SS, Dandona L, Hoisington JA, James SL, Hogan MC, Gakidou E. India's Janani Suraksha Yojana, a conditional cash transfer programme to increase births in health facilities: an impact evaluation. Lancet Lond Engl. 2010;375(9730):2009-23.

7. National Health Mission. Annual Report 201314 [Internet]. New Delhi: Department of Health \& Family Welfare, Ministry of Health \& Family Welfare, Government of India; 2014 p. 371. Available from: http://nhm.gov.in/images/pdf/media/publicatio n/Annual_Report-Mohfw.pdf

8. Sood B, Asif R, Charurat E, Das S, Kumar S, McKaig C, et al. Revitalization of postpartum IUCD (PPIUCD) services: experience from India. Contraception. 2012;86(2):184-5.

9. Casterline JB, Sinding SW. Unmet need for family planning in developing countries and implications for population policy. Popul Dev Rev. 2000;26(4):691-723.

10. Cwiak C, Gellasch T, Zieman M. Peripartum contraceptive attitudes and practices. Contraception. 2004;70(5):383-6.

11. Medical eligibility criteria wheel for contraceptive use. A WHO family planning cornerstone. [Internet]. 5th ed. Geneva: World Health Organization; 2015. 268 p. Available from:

\begin{tabular}{|c|l|}
\hline \multicolumn{2}{|c|}{ Access this Article in Online } \\
\hline & Website: \\
\hline & www.ijcrims.com \\
\hline Quick Response Code & Subject: \\
\hline
\end{tabular}

http://apps.who.int/iris/bitstream/10665/18146 8/1/9789241549158_eng.pdf

12. Grimes DA, Lopez LM, Schulz KF, Van Vliet HA, Stanwood NL. Immediate postpartum insertion of intrauterine devices. Cochrane Database Syst Rev. 2010 May 12;(5):CD003036.

13. Shukla M, Qureshi S, Chandrawati. Postplacental intrauterine device insertion--a five year experience at a tertiary care centre in north India. Indian J Med Res. 2012;136(3):432-5.

14. Chi IC, Wilkens L, Rogers S. Expulsions in immediate postpartum insertions of Lippes Loop $\mathrm{D}$ and Copper T IUDs and their counterpart Delta devices--an epidemiological analysis. Contraception. 1985;32(2):119-34.

15. Tatum HJ, Beltran RS, Ramos R, Van Kets H, Sivin I, Schmidt FH. Immediate postplacental insertion of GYNE-T 380 and GYNE-T 380 postpartum intrauterine contraceptive devices: randomized study. Am J Obstet Gynecol. 1996;175(5):1231-5.

16. Celen S, Möröy P, Sucak A, Aktulay A, Danişman N. Clinical outcomes of early postplacental insertion of intrauterine contraceptive devices. Contraception. 2004;69(4):279-82.

17. Araujo VB, Ortiz L, Smith J. Postpartum IUD in Paraguay. A case series of 3000 cases. Contraception. 2012;86(2):173-4.

18. Blumenthal P, Shiliya N, Neukom J, Chilambwe J, Vwalika B, Prager S, et al. Expulsion rates and satisfaction levels among postpartum IUD users in peri-urban Lusaka, Zambia. Contraception. 2011;84(3):320.

How to cite this article:

Preetkanwal Sibia, Parneet Kaur, Surbhi Saini, Anju. (2017). PPIUCD- Expanding Horizons in Contraception in Indian Scenario. Int. J. Curr. Res. Med. Sci. 3(6): 156161.

DOI: http://dx.doi.org/10.22192/ijcrms.2017.03.06.020 